\title{
Effects of glucose and sucrose administration on the working ability of young women
}

\author{
Ogawa $\mathrm{M}^{1}$, Shimizu $\mathrm{F}^{1}$, Ishii $\mathrm{Y}^{1}$, Takao $\mathrm{T}^{1}$ and Takada $\mathrm{A}^{2}$ \\ ${ }^{1}$ Faculty of Life and Environmental Sciences, Showa Women's University, Tokyo, Japan \\ ${ }^{2}$ International Projects on Food and Health(NPO), Tokyo, Japan
}

\begin{abstract}
Background: There have been numerous studies showing that the administration of glucose improved memory and other brain functions. Practically no study has been reported on the effect of sucrose administration on brain functions in humans.

Methods: Female college students are given $500 \mathrm{~mL}$ solutions containing each $50 \mathrm{~g}$. of glucose, sucrose, fructose or water. Blood was taken at 0.15 .30 .60$. and 120 min. later. Uchida-Kraepelin tests were administered before and 30 min. after drinks intake.

Results: Glycemic index of sucrose was $88 \%$ of glucose administration. There was a significant increase in the working ability measured by Uchida-Kraepelin test after the administration of sucrose. There was a tendency for increase in the working ability after sucrose, glucose or fructose administration but not statistically significant.

Conclusion: Sucrose administration improved the working ability of young females possibly not only by transport of glucose into the brain but the increased activity of the brain hedonic sites by the stimulation of sweet receptors, T1R 23.
\end{abstract}

\section{Introduction}

It has been shown from animal studies that increased blood glucose levels are associated with improved memory and attention. Previous studies have found human memory to be facilitated by the administration of glucose [1].

There was a significant correlation between blood glucose values and the number of words recalled. Those whose blood glucose levels were increasing remembered significantly more words than those whose blood glucose levels were falling [2].

Extensive evidence indicates that relatively modest increases in circulating glucose concentrations enhance learning and memory processes in rodents and humans [3]. In rats, systemic injections of glucose enhance learning and memory under many conditions. Although sucrose is degraded to glucose in the intestine and glucose is transported to the blood, no systematic studies have been carried about as to the effects of sucrose on brain function [4].

We have recently shown by using Morris maze experiments that sucrose enhanced memory of rats more significantly than glucose although glucose tended to enhance memory $[5,6]$. We wanted to find out effects of the intake of glucose or sucrose on the working ability using Uchida-Kraepelin tests by which we could measure the working ability of participants.

\section{Ethics}

This work has been approved by the Ethical committees of Showa Women's University and NPO "International projects on food and health" and has been carried out in accordance with The Code of Ethics of the World Medical Association (Declaration of Helsinki) for experiments.

\section{Methods}

We asked female college students to participate in the experiments. They were recruited if there were no health problems such as diabetes, hypertension or not serious diseases experienced in the past. They did not smoke in the past. We also excluded people who took drugs for dyslipidemia, hyperglycemia, or hypertension. The backgrounds of participants are shown in Table 1.

We collected blood samples early morning. Participants were asked not to eat anything after 23.00 PM the previous evening. We obtained an informed consent prior to conducting the protocol which had been approved by the Ethical Committee of Showa Women's University.

Table 1. Background of participants $(n=35)$

\begin{tabular}{|l|l|}
\hline Age & $21 \pm 1$ \\
\hline Height $(\mathrm{cm})$ & $157.3 \pm 6.1$ \\
\hline Weight $(\mathrm{kg})$ & $50.3 \pm 5.5$ \\
\hline BMI $\left(\mathrm{kg} / \mathrm{m}^{2}\right)$ & $20.3 \pm 1.5$ \\
\hline Energy intake $(\mathrm{kcal})$ & $1823 \pm 358$ \\
\hline Protein intake $(\mathrm{g})$ & $65.9 \pm 17.1$ \\
\hline Lipids intake $(\mathrm{g})$ & $63.1 \pm 16.2$ \\
\hline Carbohydrate intake $(\mathrm{g})$ & $236.1 \pm 42.9$ \\
\hline
\end{tabular}

Correspondence to: Takada A, International Projects on Food and Health (NPO), Sumida-ku Ishiwara 1-30-6-802, Tokyo 130-0011, Japan, Tel: 81338291849; Fax: 81338291847; E-mail: takadaa@mwd.biglobe.ne.jp

Key words: glucose, sucrose, insulin, Uchida-Kraepelin test, glycemic index, sweet receptor, T1R 23

Received: February 14, 2018; Accepted: February 26, 2018; Published: March 02,2018 
Healthy participants were given self-administered diet history food frequency questionnaires based on food groups by recollection of diets they took. From these questionnaires, we calculated the intakes of energy, carbohydrate, fat, and protein.

Blood glucose levels were measured by using a finger stick (TERUMO kit).

\section{Experimental schedules}

At 9 AM in the morning, blood was taken from fasting participants. They took Uchida-Kraepelin tests and drank $500 \mathrm{~mL}$ of solutions containing $50 \mathrm{~g}$. of sucrose, glucose of fructose or else $500 \mathrm{~mL}$ of water. $15 \mathrm{~min}$. after taking drinks, they participated in Uchida-Kraepelin tests, then $30,60,120 \mathrm{~min}$. after taking drinks, their bloods were taken.

Figure 1 shows the experimental schedules. We took blood at 0 min and measured blood glucose levels. Participants were engaged in Uchida-Kraepelin test and they took $500 \mathrm{~mL}$ solution containing $50 \mathrm{~g}$ of either glucose, fructose or sucrose. As a control they took $500 \mathrm{~mL}$ of water.

\section{Uchida-Kraepelin test [7]}

There are numbers of a digit lined. Two numbers lined together are added. The number of the higher digit is described. This procedure is repeated for $1 \mathrm{~min}$. Then the addition of numbers of the second line is performed. and repeated for $15 \mathrm{~min}$. The total numbers added are calculated. and compared before and after the experiment.

The working duty of $1 \mathrm{~min}$. was repeated 15 times then drinks were taken. After blood measurements at $30 \mathrm{~min}$. tests were repeated.

\section{Results}

Figure 2 shows the working ability of participants after taking glucose, fructose, sucrose or water. The intake of glucose or fructose tended to increase the working ability, but sucrose intake resulted in a significant increase in the working ability.

Participants calculated numbers in $15 \mathrm{~min}$. The number of calculations was added. The difference of the numbers of calculations before and after drinks intake was considered a working ability.

Figure 3 shows changes in blood glucose levels after sugar intakes. Blood glucose levels significantly increased after glucose or sucrose intakes. Blood glucose levels did not increase after fructose intake. Although sucrose contains $50 \%$ of glucose in the molecule, blood glucose levels increased more than $50 \%$. When glycemic index was calculated for sucrose, it was $88 \%$ of glucose. Figure 4 shows relationship between working ability and blood glucose levels.

We compared the working ability and blood glucose levels of all participants at $30 \mathrm{~min}$. after the administration of sugars or water.

The working ability of participants tended to increase when blood glucose levels increased, but there was no statistical significance. There was no significant correlation coefficient $(=0.53)$ between blood glucose levels and the working ability after taking drinks.

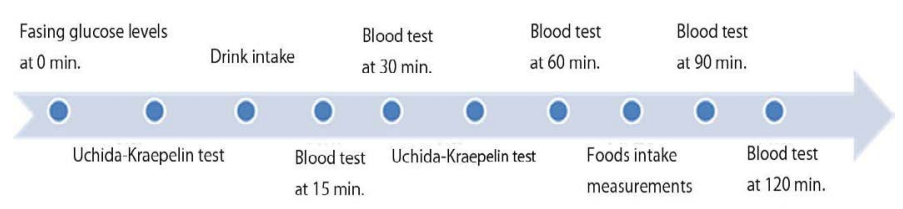

Figure 1. The schedule of experiments

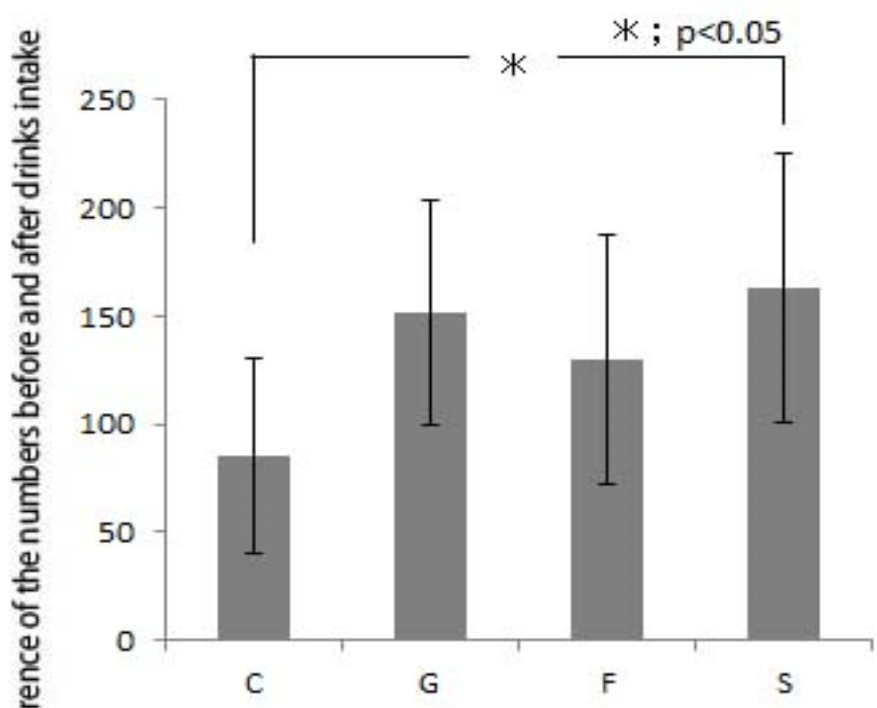

The working ability and sugar intakes

Figure 2. The working ability after each drink (The working ability after each drink was examined by Uchida-Kraepelin test. C: Control; G: Glucose administration; S: Sucrose administration; F: Fructose administration)

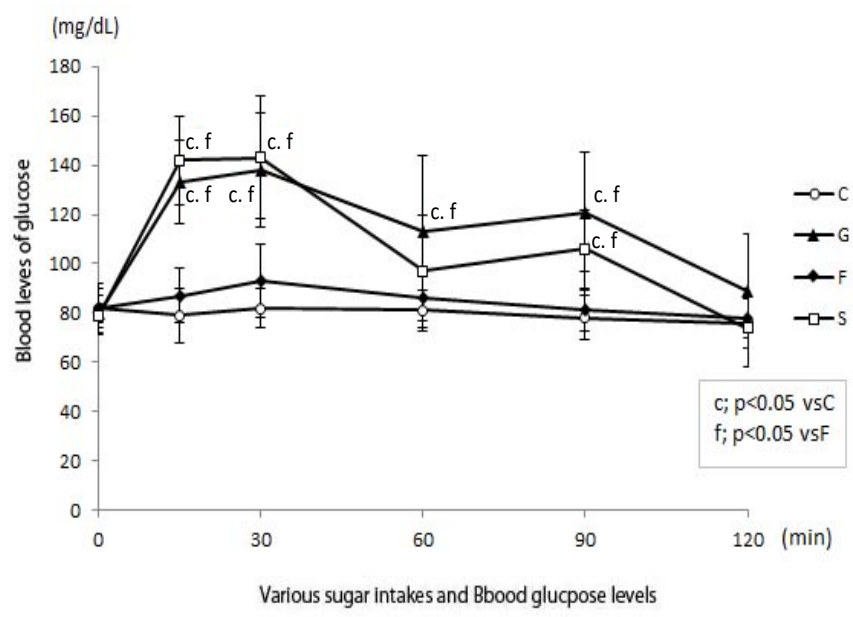

Figure 3. Time courses of blood glucose levels after taking each drink (C: Control; G: Glucose administration; S: Sucrose administration; F: Fructose administration; c: G, S vs. C, f: G, S vs. F)

When the relationship between the working ability and blood glucose levels after drinking glucose, fructose, sucrose or water measured, there were no significant relationships between the working ability and blood glucose levels. No correlation coefficients were found between the working ability and blood glucose levels after each drink (Figure 5).

\section{Discussion}

It is well established that glucose is a major fuel of the brain and transported across the cell membranes by facilitated diffusion mediated by glucose transporter proteins [8]. Injections of glucose have been shown to enhance memory in a variety of tasks [9-16]. Sucrose is composed by glucose and fructose and degraded to its components in the intestine and glucose is absorbed into the blood.

We have administered sucrose or glucose to young and old men and found that glycemic index in response to sucrose was $82.8 \%$ 


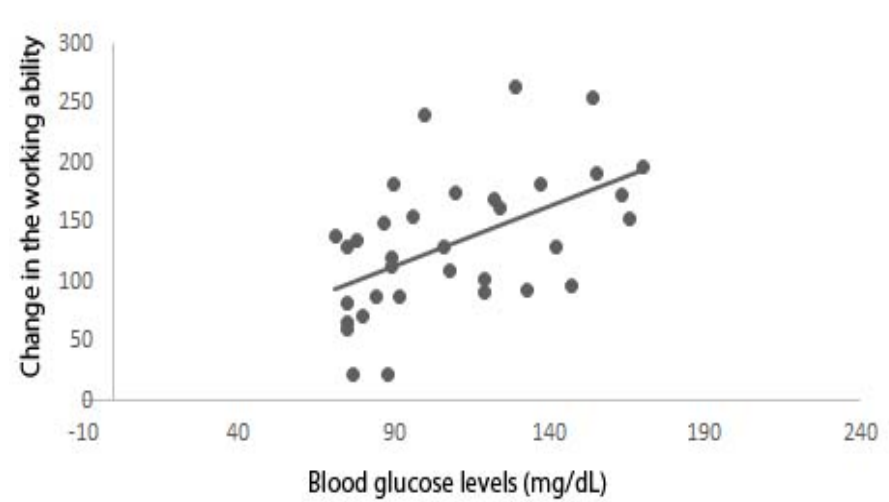

Figure 4. Plot diagram between blood glucose levels and working ability (Correlation coefficients: plasma glucose levels vs. working ability for all participants $=0.53$. G vs. working ability $=0.22, \mathrm{~F}$ vs. working ability $=0.19, \mathrm{~S}$ vs, working ability $=0.37$. None is statistically significant)

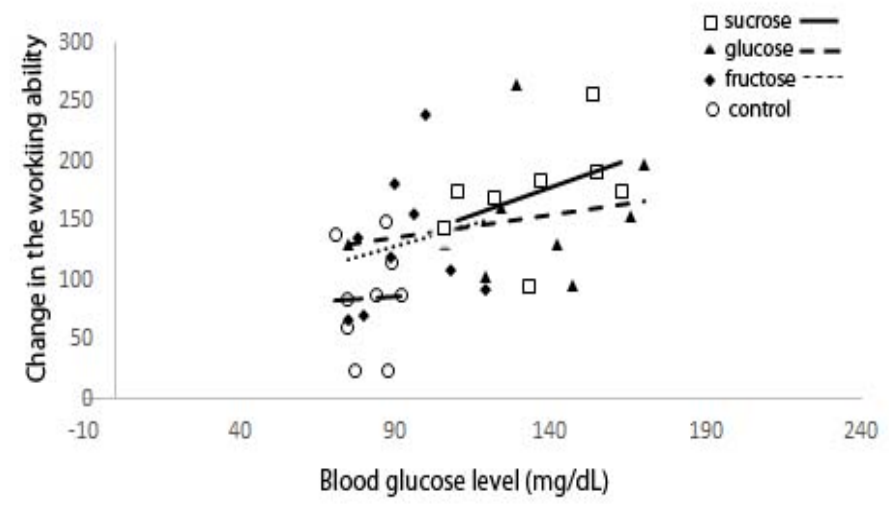

Figure 5. Plot diagrams between blood glucose levels after taking sucrose, glucose or fructose and working ability

compared to that of glucose in the younger men and $73.5 \%$ in the older men. These results mean that sucrose administration increases significantly blood glucose levels [17]. These results were obtained by the administration of sucrose or glucose to young and old women [18].

So far, no research has been performed about the effects of sucrose administration on the mental activity.

As indicated before we reported using Morris maze experiments that sucrose, but not glucose administration improved memory of rats $[5,6]$.

We used Uchida-Kraepelin test to know about the working ability and found that sucrose administration resulted in significant increase in the working ability of young women. Although there was a tendency for the working ability to increase after glucose or fructose administration, but statistical significance was shown.

Since there was a tendency for the working ability to increase after the administration of fructose although slight increase in glucose levels was seen, we thought that sweet taste may contribute to increase in the working ability.

It has been shown that the stimulation of sweet taste resulted in increase in dopamine release in N. Accumbens and caused hedonic responses [19]. Fructose receptors of the tongue are T1R 23 , which is the same for sucrose receptors [20].

We examine how blood glucose levels influenced the working ability after the administration of sugars. Figures 3 and 4 show that although there was a tendency for increase in the working ability after sugar administration, no statistical significance was obtained about correlations between them.

These results suggest that although glucose increases the working ability, the role of sweet taste in this ability may not be ignored.

\section{Statistics}

The results are presented as means \pm SD. Statistical significance of the differences between groups was calculated according by one-way ANOVA. When ANOVA indicated a significant difference $(\mathrm{P}<0.05)$, the mean values of the treatment were compared using Tukey's least significant difference test at $\mathrm{P}<0.05$. Spearman's correlation tests were used to examine statistical significance.

\section{Acknowledgment}

Experiments were designed and performed by all the authors. AT wrote a manuscript. Statistical analyses were done by MO. All authors read the manuscript and approved the final version. All the authors had responsibilities for the final content. No conflicts of interest for any author.

\section{Financial support}

This study was supported by Ito Memorial Foundation, NPO "International Projects on Food and Health." and the grant of Showa Women's University.

\section{References}

1. Benton D, Owen DS, Parker PY ((1994) Blood glucose influences memory and attention in young adults. Neuropsychologia 32: 595-607. [Crossref]

2. Benton D, Owens DS (1993) Blood glucose and human memory. Psychopharmacology (Berl) 113: 83-88. [Crossref]

3. Gold PE (1995) Role of glucose in regulating the brain and cognition. Am J Clin Nutr 61: 987S-995S. [Crossref]

4. van der Zwaluw NL, van de Rest O, Kessels RP, de Groot LC (2014) Short-term effects of glucose and sucrose on cognitive performance and mood in elderly people. $J$ Clin Exp Neuropsychol 36: 517-527. [Crossref]

5. Shinohara K, Hata T, Ishii Y, Takao T, Ogawa M, et al. (2015) Effects of glucose and sucrose administration on memory function. Starch and sucrose information. Agriculture and Livestock Industries Corp. http://www.alic.go.jp/joho-s/joho07_001138.html.

6. Takada A, Ishii Y, Takao T, Ogawa M, Shimizu F, et al. (2017) How the brain utilizes glucose? Antiaging Medicine 13: 96-103.

7. Sugimoto K, Kanai A, Shoji N (2009) The effectiveness of the Uchida-Kraepelin test for psychological stress: an analysis of plasma and salivary stress substances. Biopsychosoc Med 3: 3-5. [Crossref]

8. Duelli R, Kuschinsky W (2001) Brain glucose transporters: relationship to local energy demand. News Physiol Sci 16: 71-76. [Crossref]

9. Messier C, White NM (1987) Memory improvement by glucose, fructose and two glucose analogs: a possible effect on peripheral glucose transport. Behav Neural Biol 48: 104-127. [Crossref]

10. Messier C, Destrade C (1988) Improvement of memory for an operant response by post-training glucose in mice. Behav Brain Res 31: 185-191. [Crossref]

11. Messier C, Durkin T, Mirabet O, Destrade C (1990) Memory-improving action of glucose: indirect evidence for a facilitation of hippocampal acetylcholine synthesis. Behav Brain Res 39: 135-143. [Crossref]

12. Packard MG, White NM (1990) Effect of post training injections of glucose on acquisition of two appetitive learning tasks. Psychobiol 18: 282-286.

13. Means LW, Fernandez TI (1992) Daily glucose injections facilitate performance of a win-stay water-escape working memory task in mice. Behav Neurosci 106: 345-350. [Crossref]

14. Rodriguez WA, VanAusdle LR, Dhanens K (1993) Mondragon AN. Glucose modulates recently reactivated memories. Psychobiol 21: 93-100. 
15. Ahlers ST, Shurtleff D, Schrot J, Thomas JR, Paul-Emile F (1993) Glucose attenuates cold-induced impairment of delayed matching-to-sample performance in rats. Psychobiol 21: 87-92.

16. Kopf SR, Opezzo JW, Baratti CM (1993) Glucose enhancement of memory is not statedependent. Behav Neural Biol 60: 192-195. [Crossref]

17. Takao T, Ogawa M, Ishii Y, Shimizu F, Takada A (2016) Different glycemic responses to sucrose and glucose in old and young male adults. J Nutr Food Sci 6: 460
18. Takada A, Ishii Y, Shimizu F, Ogawa M, Takao T (2016) Gender and age differences of glycemic index in Japanese old men, young men and women. Integr Food Nutr Metab 4: 438-440.S

19. Berridge $\mathrm{KC}$ (2000) Measuring hedonic impact in animals and infants: microstructure of affective taste reactivity patterns. Neurosci Biobehav Rev 24: 173-198. [Crossref]

20. Nelson G, Hoon MA, Chandrashekar J, Zhang Y, Ryba NJ, et al. (2001) Mammalian sweet taste receptors. Cell 106: 381-390. [Crossref]

Copyright: (2018 Ogawa M. This is an open-access article distributed under the terms of the Creative Commons Attribution License, which permits unrestricted use, distribution, and reproduction in any medium, provided the original author and source are credited. 